\title{
Rate of metabolism during lactation in small terrestrial mammals (Crocidura russula, Mus domesticus and Microtus arvalis)
}

\author{
Cédric Cretegny, Michel Genoud* \\ Département d'Ecologie et d' Evolution, Bâtiment de Biologie, Université de Lausanne, CH-1015 Lausanne, Switzerland
}

Received 7 April 2005; received in revised form 10 October 2005; accepted 11 October 2005

Available online 19 April 2006

\begin{abstract}
Basal rate of metabolism (BMR) and resting maternal rate of metabolism around peak lactation ( $\left.\mathrm{RMR}_{\mathrm{L}}\right)$ were measured in Crocidura russula, Mus domesticus and Microtus arvalis. These species have a moderate or high BMR relative to the scaling relationship of Kleiber. One goal of the study was to check whether females of these species show elevated rates of metabolism during lactation. A second goal was to test for a possible intraspecific correlation between the level of BMR and the change in rate of metabolism associated with lactation. $\mathrm{RMR}_{\mathrm{L}}$ was significantly higher than BMR in all species when changes in body mass between the two states were taken into account. Data available on other small mammals are in accordance with this finding, which does not support the hypothesis that low-BMR mammal species increase their rate of metabolism during reproduction because Kleiber's relationship represents an optimal level for therian reproduction. Within C. russula and M. domesticus, a significant and negative correlation was found between the level of BMR and the change in rate of metabolism associated with lactation. This pattern is presumably due to the fact that low-BMR females undergo more extensive physiological and anatomical changes during lactation than high-BMR females.
\end{abstract}

(C) 2006 Elsevier Inc. All rights reserved.

Keywords: White-toothed shrew; House mouse; Common vole; Small mammal; Metabolic rate; BMR; Maternal rate of metabolism; Reproduction; Lactation; Intraspecific variation

\section{Introduction}

The energetic cost of reproduction is a central aspect of reproduction in small mammals. When they are pregnant or lactating, females channel appreciable (and often very large) amounts of the ingested energy into new tissues or milk that is distributed to the offspring (Randolph et al., 1977; Weiner, 1987; Mover et al., 1989; Genoud and Vogel, 1990; Thompson, 1992; Rogowitz and McClure, 1995; Künkele and Trillmich, 1997; McNab, 2002; Liu et al., 2003). This energy, which is allotted to production, is not considered when measuring rate of metabolism. However, there are two aspects of the energy cost of production: energy must be sequestered into the new tissues or milk, and additional energy is required for the work of production (Gessaman, 1973). Thus, the rate of metabolism of reproducing females may be more or less affected by the physiological changes associated with reproduction.

\footnotetext{
* Corresponding author. Fax: +41216924165.

E-mail address: mgenoud@vtxnet.ch (M. Genoud).
}

Basal rate of metabolism (BMR) is defined as the minimum rate of metabolism of an endothermic animal measured under a number of restrictive conditions: individuals must be adults resting within the thermoneutral zone, neither digesting food nor (for females) being involved in reproduction (McNab, 1997). Despite such a precise definition, this physiological parameter exhibits a large degree of variation among mammals, only part of which is linked to body mass (Kleiber, 1961; $\mathrm{McNab}$, 1988). Allometric equations (e.g. Kleiber, 1961 or $\mathrm{McNab}$, 1988) are commonly used to calculate the "relative BMR" of a species under study by expressing its BMR as a percentage of the value expected on the basis of its body mass. The variation in relative BMR among mammals has been analyzed by many authors and its interpretation remains controversial (see McNab, 2002, for a review). In particular, McNab (1980) proposed that a high relative BMR may permit a high reproductive output, through higher growth rate of pups, higher milk production, higher fecundity or a combination of these. This proposal has been the subject of an ongoing debate, either at an interspecific level or at an intraspecific level (Hennemann, 
1983; Hayssen, 1984; Glazier, 1985; Derting, 1989; Derting and McClure, 1989; Earle and Lavigne, 1990; Harvey et al., 1991; Hayes et al., 1992; Stephenson and Racey, 1993a; Speakman and McQueenie, 1996; McLean and Speakman, 2000; Johnson et al., 2001a; McNab, 2002; Krol et al., 2003).

Thompson and Nicoll (1986) and Nicoll and Thompson (1987) observed that females of three mammalian species with a low BMR (Monodelphis domestica, Echinops telfairi and Elephantulus rufescens) strongly increased their rate of metabolism during reproduction, with maximum values achieved during lactation. In contrast, data from the literature suggested no such increase in a few species with a moderate or high BMR. This difference between low-BMR and high-BMR species led Thompson and Nicoll (1986) to hypothesize that predicted $\mathrm{BMR}$ according to the Kleiber equation $(\mathrm{BMR}=$ $3.42 \mathrm{~m}^{0.75}$, where BMR is in $\mathrm{mLO}_{2} \mathrm{~h}^{-1}$ and $m$ is body mass in g) may reflect an "advantageous or essential energetic regime" for therian reproduction and to propose that this is the reason why mammals with a low BMR relative to the Kleiber equation must increase their rate of metabolism during reproduction. Indeed, their hypothesis is supported by the increased rate of metabolism of low-BMR species during reproduction only if high-BMR species do not show such an increase. However, more recent studies showed diverse patterns of metabolic change during reproduction in species with a moderate or high BMR, including maternal rates of metabolism clearly above nonreproductive levels (Thompson, 1992; Stephenson and Racey, 1993a; Speakman and McQueenie, 1996; Antinuchi and Busch, 2001).

It has also been suggested that the rate of metabolism for a whole individual can be increased in reproducing female mammals as a consequence of the increase in size and/or activity of specific organs or tissues, such as the mammary glands or the intestine (Hammond and Diamond, 1992; Thompson, 1992; Hammond et al., 1994; Speakman and McQueenie, 1996). If this was the main cause of elevated maternal rate of metabolism, low-BMR and high-BMR species should not exhibit the drastically different patterns of metabolic change during reproduction that have been hypothesized by Thompson and Nicoll (1986). Furthermore, appreciable intraspecific variation in BMR or maternal rate of metabolism has often been noticed (Derting and McClure, 1989; Earle and Lavigne, 1990; Hayes et al., 1992; McLean and Speakman, 2000), but the possible relationship between the level of BMR and the pattern of change in maternal rate of metabolism among conspecific females has yet to be examined.

In the present study, we provide new data on the BMR and the maternal rate of metabolism measured during lactation $\left(=\mathrm{RMR}_{\mathrm{L}}\right.$; Thompson, 1992) in three species of small terrestrial mammals, the white-toothed shrew Crocidura russula (Soricidae, Eulipotyphla) the (wild) house mouse Mus domesticus (Muridae, Rodentia) and the common vole Microtus arvalis (Cricetidae, Rodentia). These small mammals have a BMR that is either close to or above the value predicted by the Kleiber equation (Rosenmann and Morrison, 1974; Sparti, 1990; Richardson et al., 1994; Cretegny, 1997). We address two main questions: firstly, does $\mathrm{RMR}_{\mathrm{L}}$ differ from BMR in these three species? Secondly, is the variation in metabolic change between the two states (lactating vs. neither pregnant nor lactating) correlated with variation in BMR among conspecific females? Because females may exhibit a different body mass in these two reproductive states and because body mass is known to affect rate of metabolism, it is obviously necessary to control for the confounding effects of body mass to answer these questions.

\section{Materials and methods}

\subsection{Animals and maintenance conditions}

Nineteen female $C$. russula (average body mass, $m=11.3 \pm$ $1.5 \mathrm{~g}(\mathrm{SD})), 24$ female $M$. domesticus ( $m=22.8 \pm 2.2 \mathrm{~g}$ ) and 11 female $M$. arvalis $(m=33.9 \pm 7.9 \mathrm{~g})$, were used in this study. The shrews were caught in winter in the vicinity of Lausanne (western Switzerland, 400-600 m elevation). In this region, the reproductive season of $C$. russula normally extends from early spring to fall (Jeanmaire-Besançon, 1988) and females participate only exceptionally in two successive reproductive seasons (Jeanmaire-Besançon, 1986), so that the individuals caught can be assumed to be nulliparous and born in the previous summer or fall. All mice and voles were first-generation offspring of individuals caught in the vicinity of Lausanne. The reproductive season of M. arvalis is similar to that of C. russula in this region (personal observations, C.C.), that of M. domesticus extending probably throughout the year where favourable conditions are met (Hübner, 1995). The taxonomy of the European mice is still debated, but populations from Switzerland belong to the West-European long-tailed commensal form usually referred to as M. domesticus (Hübner, 1995; Macholan, 1999). Females of all three species were kept individually or paired with males originating from the same populations (see below for details) in cages of $38 \times 22 \mathrm{~cm}$ in an animal room with an ambient temperature of $20-22^{\circ} \mathrm{C}$ and a long-day photoperiod (16L:8D) corresponding to summer conditions. Cage floors consisted of earth for shrews and wood shavings for rodents. Hay was given as nesting material to all species and a nest box was provided to the shrews and voles. Food and water were given ad libitum. In the case of shrews, food consisted of minced horsemeat mixed with grated carrots, and a mineral and vitamin supplement for insectivores (Eberle Nafag, Gossau, Switzerland). The rodents received dry pellets (type 924/ 25W10, Eberle Nafag, Gossau, Switzerland), but they also consumed variable quantities of the dry hay given as nesting material. In addition, voles received seeds and a piece of carrot on a daily basis.

\subsection{Experiments}

The rate of metabolism of each female was measured during the reproductive season in two reproductive states: (1) while neither pregnant nor lactating (hereafter referred to as the NL state), and (2) around peak lactation (the L state). All measurements were made under conditions meeting the requirements for BMR, except for the reproductive activity in the L state. Rates of metabolism measured during lactation are therefore referred to 
as resting rates of metabolism $\left(\mathrm{RMR}_{\mathrm{L}}\right.$; Thompson, 1992). Throughout this paper, the NL state corresponds to the condition shown by adult females within the reproductive season, which are ready to reproduce but are neither pregnant nor lactating. This eliminates a number of potential sources of variation in rate of metabolism, including particularly seasonal variations (Genoud, 1990; Merrit et al., 2001). In order to avoid the difficulty of determining whether a nulliparous female was in a physiological state appropriate for reproduction or not, BMR was not measured in nulliparous females, but in females that had successfully raised at least one litter. It was measured at least one week after weaning of the preceding litter and subject to the condition that the female was not pregnant (male removed before parturition of the preceding litter).

The $\mathrm{RMR}_{\mathrm{L}}$ was measured during the second to sixth litter of each female, during summer or fall. The first litter was never used since primiparous females differ from more experienced females in their patterns of energy acquisition and allocation (e.g. see Genoud and Vogel, 1990, for C. russula; Cretegny, 1997, for M. arvalis). C. russula and M. domesticus mothers were not pregnant at the time of $\mathrm{RMR}_{\mathrm{L}}$ measurement (males removed at parturition), but in $M$. arvalis males were not separated at parturition, such that most mothers were simultaneously pregnant and lactating. Furthermore, in order to standardize reproductive effort, litters were adjusted at parturition to 4 young, which is a little below average litter size for all three species in the region of Lausanne (Genoud and Vogel, 1990; Cretegny, 1997; personal observations). $\mathrm{RMR}_{\mathrm{L}}$ measurements took place around peak lactation (Genoud and Vogel, 1990; Cretegny, 1997; personal observations), between days 7 and 11 postpartum (the day of parturition is day 0) in C. russula, between days 8 and 12 in M. domesticus and during day 10 in $M$. arvalis. Litters were weighed on the day of $\mathrm{RMR}_{\mathrm{L}}$ measurement. In addition, they were also weighed on day 10 in C. russula and M. domesticus, when $\mathrm{RMR}_{\mathrm{L}}$ was measured on a different day.

\subsection{Rate of metabolism}

Rate of metabolism was measured as oxygen consumption and is hereafter expressed in $\mathrm{mLO}_{2} \mathrm{~h}^{-1}$. Experiments were conducted at $31{ }^{\circ} \mathrm{C}$, which is within the thermoneutral zone for all three species (Sparti, 1990 for C. russula; Rosenmann and Morrison, 1974 and Genoud, unpublished data for M. domesticus; Cretegny, 1997 for M. arvalis). Females were removed from their cages in the morning and introduced into the respirometric chamber. Values were taken only after a period allowing for the digestion of the food that the animals may have eaten in the morning, i.e. after $3 \mathrm{~h}$ for the shrews and $6 \mathrm{~h}$ for the two rodent species. After this time lapse, a measure was taken during a period of at least $15 \mathrm{~min}$ of stable and minimal oxygen consumption corresponding to a period of inactivity of the individual.

The respirometric system used is an open air-flow system that has been described previously (Sparti and Genoud, 1989; Genoud and Ruedi, 1996). Animals were placed in a $1.0 \mathrm{~L}$ (C. russula) or $3.5 \mathrm{~L}$ (M. domesticus and M. arvalis) respirometric chamber submersed in a water bath at $31{ }^{\circ} \mathrm{C}$. Air was pushed through this chamber by a pump at a regulated flow rate of 15
$27 \mathrm{~L} \mathrm{~h}^{-1}$ STPD depending on the size of the animal. After the chamber, the air passed through soda lime and silica gel to remove carbon dioxide and water, and then through a Brooks Sho-Rate flow meter (Veenendaal, Netherlands) calibrated for the operating temperature and pressure conditions. Part of the air was then passed through a two-way oxygen analyser (OA184 Taylor Servomex, Crowborough, England or S-3A/11 Ametek, Pittsburgh, PA, USA) to measure its oxygen concentration. Oxygen consumption was calculated according to formula 10 in Depocas and Hart (1957).

\subsection{Statistics}

Unless otherwise stated, values are expressed as means and standard deviation. Relative BMR is BMR expressed as a percentage of the value expected according to Kleiber's equation (Kleiber, 1961), because this was the scaling equation used by Thompson and Nicoll (1986). Equations derived more recently from a much larger number of mammal species (McNab, 1988) would not change any of the conclusions of the present paper. All statistical tests were carried out on $\log _{10}$-transformed data to prevent heteroscedasticity and to linearize the relationship between rate of metabolism and body mass.

As every female had been measured in both reproductive states, the effect of reproductive state on rate of metabolism in each species was tested with a repeated measures ANCOVA. The software "R" (or "GNU S"; Thaka and Gentleman, 1996) was used: it allows for a variation of the covariable across the factor within subjects. $\log _{10}$ rate of metabolism was the dependent variable and $\log _{10}$ female body mass was the covariable. Reproductive state was a within-subjects factor, individual females being the "subjects". There are two levels of analysis in such ANCOVAs: a "between-subjects" level and a "withinsubjects" level. In this case, the null hypothesis was that $\log _{10}$ rate of metabolism would not be affected by reproductive state within subjects (individuals). Litter mass may have affected $\mathrm{RMR}_{\mathrm{L}}$ even if litter size was standardized and although such an influence has generally not been found in earlier studies (e.g. see Krol et al., 2003). Because $\mathrm{RMR}_{\mathrm{L}}$ was not necessarily measured on the same day in C. russula and M. domesticus, litter mass measured on the day of $\mathrm{RMR}_{\mathrm{L}}$ measurement depended strongly on the age of the young in these species. It was not correlated with $\operatorname{RMR}_{\mathrm{L}}(P>0.1$ in both cases). Litter mass measured on day $10\left(=m_{\mathrm{Y}}\right)$ was used instead as a comparative index of the energetic load imposed on the female by its litter. However, $m_{\mathrm{Y}}$ was significantly correlated with female mass (see below), which is the covariable. Thus, when $\mathrm{RMR}_{\mathrm{L}}$ was correlated with $m_{\mathrm{Y}}$ independently of female body mass (partial correlation analyses), residuals of the linear regression between $\log m_{\mathrm{Y}}$ and $\log m_{\mathrm{L}}$ were calculated $\left(=\operatorname{res} m_{\mathrm{Y}} ; m_{\mathrm{L}}\right.$ is female body mass during lactation) and a similar ANCOVA was done on $\mathrm{RMR}_{\mathrm{L}}$ values corrected for an average residual.

At the intraspecific level, testing of the hypothesized correlation between the change in rate of metabolism between the two reproductive states $\left(\mathrm{RMR}_{\mathrm{L}}-\mathrm{BMR}\right)$ and the level of BMR compared to other conspecific females was done with partial correlation analyses controlling for body mass effects. 
Table 1

Body mass, BMR (NL state) and $\mathrm{RMR}_{\mathrm{L}}$ during peak lactation (L state) in three species of small mammals

\begin{tabular}{|c|c|c|c|}
\hline & Crocidura russula & Mus domesticus & Microtus arvalis \\
\hline$N$ & 19 & 24 & 11 \\
\hline \multicolumn{4}{|l|}{ NL state } \\
\hline Body mass (g) & $11.3 \pm 1.5$ & $22.8 \pm 2.2$ & $33.9 \pm 7.9$ \\
\hline $\begin{array}{l}\mathrm{BMR} \\
\qquad\left(\mathrm{mL} \mathrm{O}_{2} \mathrm{~h}^{-1}\right)\end{array}$ & $22.4 \pm 2.0$ & $35.3 \pm 4.8$ & $61.4 \pm 7.1$ \\
\hline $\begin{array}{l}\text { Relative } \\
\text { BMR (\%) }\end{array}$ & 106 & 99 & 128 \\
\hline $\log \mathrm{BMR}=$ & $0.84+0.48 \log m$ & $0.28+0.93 \log m$ & $1.20+0.38 \log m$ \\
\hline $\mathrm{SE}_{\mathrm{a}} ; \mathrm{SE}_{\mathrm{b}} ; r^{2} ; P$ & 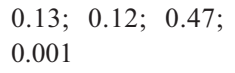 & $\begin{array}{l}0.30 ; 0.22 ; 0.45 \\
<0.001\end{array}$ & $\begin{array}{l}0.14 ; 0.09 ; 0.65 ; \\
<0.01\end{array}$ \\
\hline
\end{tabular}

$L$ state

$\begin{array}{llll}\text { Body mass }(\mathrm{g}) & 12.8 \pm 1.3 & 24.9 \pm 2.0 & 28.6 \pm 6.7 \\ \text { RMR }_{\mathrm{L}} & 32.1 \pm 3.6 & 44.4 \pm 3.7 & 66.3 \pm 8.2\end{array}$

$\left(\mathrm{mL} \mathrm{O}_{2} \mathrm{~h}^{-1}\right)$

Relative $\mathrm{RMR}_{\mathrm{L}} 139$ (\%)

$\log \mathrm{RR}_{\mathrm{L}}=\quad 0.52+0.89 \log m \quad 0.58+0.76 \log m \quad 1.14+0.47 \log m$ $\mathrm{SE}_{\mathrm{a}} ; \mathrm{SE}_{\mathrm{b}} ; r^{2} ; P \quad 0.19 ; 0.17 ; 0.61 ; 0.24 ; 0.17 ; 0.48 ; 0.16 ; 0.11 ; 0.67$; 0.0001 $<0.001$ $<0.01$

Relative BMR and $\mathrm{RMR}_{\mathrm{L}}$ are rates of metabolism expressed as a percentage of the value predicted on the basis of body mass $(\mathrm{m})$ according to the equation of Kleiber $\left(1961 ; \mathrm{BMR}=3.42 \mathrm{~m}^{0.75}\right.$, where BMR is in $\mathrm{mL} \mathrm{O}_{2} \mathrm{~h}^{-1}$ and $m$ in $\left.\mathrm{g}\right)$. The linear regressions of $\mathrm{BMR}$ and $\mathrm{RMR} \mathrm{L}_{\mathrm{L}}$ against body mass are also given $\left(\log _{10^{-}}\right.$ transformed values), with the standard errors of the constant $\left(\mathrm{SE}_{\mathrm{a}}\right)$ and slope $\left(\mathrm{SE}_{\mathrm{b}}\right)$ as well as $r^{2}$ and the significance level $P$ of the regression.

The analyses were complicated by the fact that this metabolic change may be influenced by female body mass, by body mass changes of the female between the two states, as well as by litter mass. Five variables were therefore used: $\log m_{\mathrm{NL}}$, where $m_{\mathrm{NL}}$ is female body mass in the NL state; $\log \Delta m=\log \left(m_{\mathrm{L}}-m_{\mathrm{NL}}\right)$; res $m_{\mathrm{Y}}$; resBMR, the residual of the linear regression between $\log \mathrm{BMR}$ and $\log m_{\mathrm{NL}}$; and $\log \Delta \mathrm{MR}=\log \left(\mathrm{RMR}_{\mathrm{L}}-\mathrm{BMR}\right)$. The

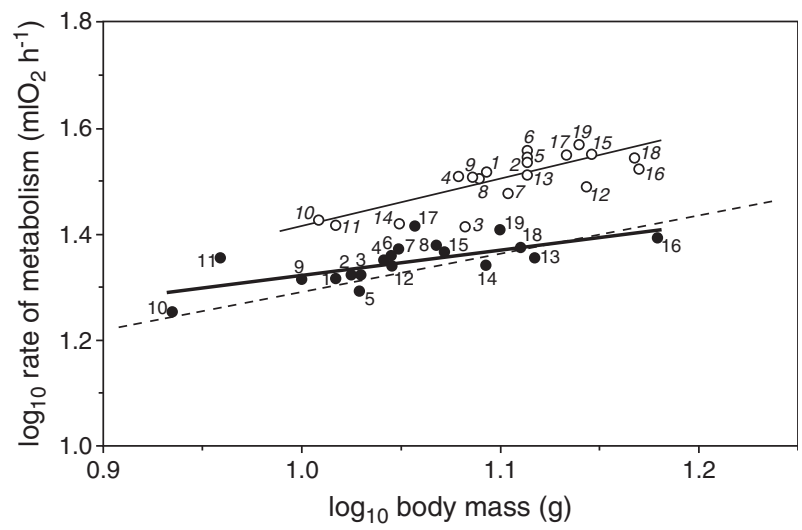

Fig. 1. Rate of metabolism (measured as oxygen consumption) as a function of body mass in 19 adult female Crocidura russula measured while neither pregnant nor lactating (NL state; closed symbols $=\mathrm{BMR}$ ) and around peak lactation $\left(\mathrm{L}\right.$ state; open symbols $=\mathrm{RMR}_{\mathrm{L}}$ ). Individuals are numbered $(\mathrm{NL}$ state in standard type, $\mathrm{L}$ state in italics). Thick and thin continuous lines are the linear regressions through BMR and $\mathrm{RMR}_{\mathrm{L}}$ values (Table 1), respectively, and dashed line is the scaling equation of Kleiber (1961). partial correlation between $\log \Delta \mathrm{MR}$ and resBMR was then calculated, while controlling for the other variables.

Differential degrees of relatedness within a population might lead to conflict with the statistical requirement of independence between individuals in both the ANCOVA and the partial correlation analysis. Unfortunately, no information was available on the relatedness between the individuals measured. However, despite some heritable variation appears to be present for BMR in laboratory mice, rate of metabolism and other related physiological traits have been shown to exhibit low heritabilities (for a discussion see Ksiazek et al., 2004). This suggests that the confounding effect of differential degrees of relatedness among individuals should be small in our analyses.

\section{Results}

\section{1. $B M R$ and $R M R_{L}$}

Average BMR was slightly above the value expected on the basis of Kleiber's equation in C. russula, close to the predicted value in $M$. domesticus, and appreciably higher than the expected value in $M$. arvalis (Table 1 and Figs. 1-3). Slightly higher values would be obtained by using McNab's (1988) equation for 272 Eutherians $(112 \%, 107 \%$ and $140 \%$ of expected, respectively). Metabolic variability within each species was large, the coefficient of variation being respectively $8.9 \%$, $13.6 \%$ and $11.6 \%$ in the three species (Table 1). Even relative BMR varied strongly, with ranges of $95-127 \%$ of the predicted value in C. russula, 80-122\% in M. domesticus, and 109-151\% in $M$. arvalis. Lactation had a roughly similar effect on rate of metabolism in the three species (Figs. 1-3). On average, $\mathrm{RMR}_{\mathrm{L}}$ exceeded BMR by $9.7,9.1$ and $4.9 \mathrm{mLO}_{2} \mathrm{~h}^{-1}$ in C. russula, $M$. domesticus and $M$. arvalis, respectively (Table 1). It remained higher than the BMR even when expressed as a percentage of Kleiber's equation (Table 1), with ranges of $117-154 \%$ of

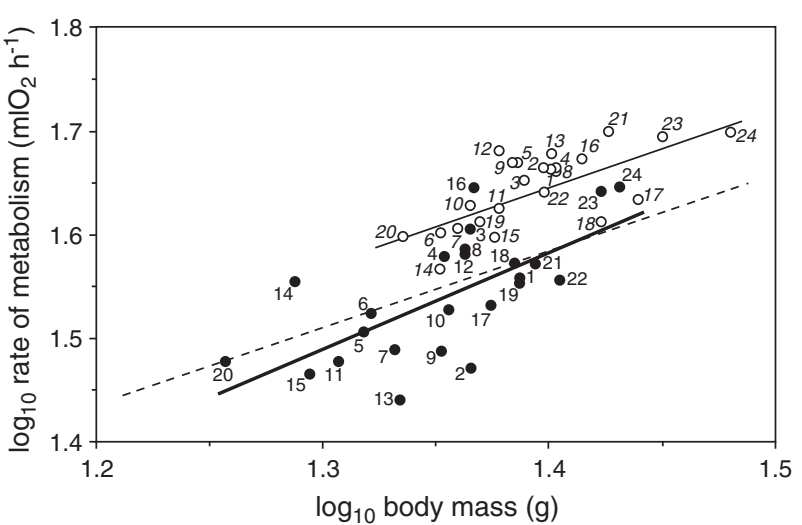

Fig. 2. Rate of metabolism (measured as oxygen consumption) as a function of body mass in 24 adult female Mus domesticus measured while neither pregnant nor lactating $(\mathrm{NL}$ state; closed symbols $=\mathrm{BMR})$ and around peak lactation $(\mathrm{L}$ state; open symbols $=\mathrm{RMR}_{\mathrm{L}}$ ). Individuals are numbered (NL state in standard type, $\mathrm{L}$ state in italics). Thick and thin continuous lines are the linear regressions through BMR and $\mathrm{RMR}_{\mathrm{L}}$ values (Table 1), respectively, and dashed line is the scaling equation of Kleiber (1961). 


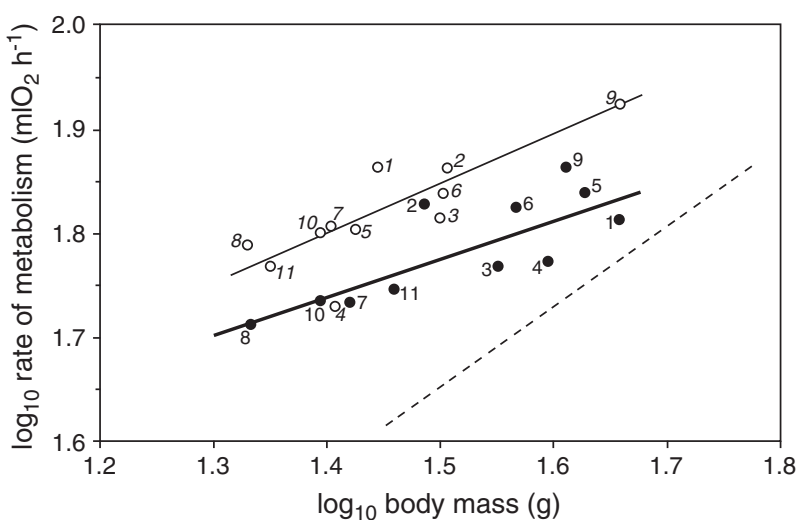

Fig. 3. Rate of metabolism (measured as oxygen consumption) as a function of body mass in 11 adult female Microtus arvalis measured while neither pregnant nor lactating $(\mathrm{NL}$ state; closed symbols $=\mathrm{BMR})$ and around peak lactation $(\mathrm{L}$ state; open symbols $\left.=\mathrm{RMR}_{\mathrm{L}}\right)$. Individuals are numbered $(\mathrm{NL}$ state in standard type, $\mathrm{L}$ state in italics). Thick and thin continuous lines are the linear regressions through BMR and $\mathrm{RMR}_{\mathrm{L}}$ values (Table 1), respectively, and dashed line is the scaling equation of Kleiber (1961).

predicted in C. russula, $102-130 \%$ in M. domesticus, and 138$181 \%$ in $M$. arvalis.

In $M$. arvalis, female body mass was slightly lower during lactation than in the NL state (Table 1; paired samples $t$-test; $t=2.52, d f=10, P<0.05)$. In contrast, it was higher during lactation in both $C$. russula $(t=6.08, d f=18, P<0.001)$ and $M$. domesticus $(t=7.31, d f=23, P<0.001)$. Therefore, at least in the two latter species, changes in body mass might account for all or part of the metabolic difference between reproductive states. Indeed, BMR was significantly related to body mass within each species, with body mass explaining $47 \%, 45 \%$ and $65 \%$ of the overall BMR variation in C. russula, M. domesticus and $M$. arvalis, respectively (linear regressions; Table 1). The same was true for $\mathrm{RMR}_{\mathrm{L}}$, with body mass making similar contributions to the metabolic variation among the lactating females $(61 \%, 48 \%$ and $67 \%$ for the three species; Table 1). This confirmed that changes in body mass must be controlled for when comparing BMR and $\mathrm{RMR}_{\mathrm{L}}$.

The repeated measures ANCOVA gave similar results in the three species (Table 2). The reproductive state had a highly significant effect on rate of metabolism at the "within-individuals level" of analysis $(P<0.01$ in all species $)$. The effect of body mass was also highly significant in all species at the "betweenindividuals" level $(P<0.001)$. At the "within-individuals level" it was significant in $C$. russula and $M$. domesticus $(P<0.0001)$, but not in $M$. arvalis $(P>0.05)$. The interaction between reproductive state and body mass was never significant $(P>0.05)$ but it approached the significance limit at the "between-individuals" level in C. russula and M. arvalis. Litter mass on day $10\left(=m_{\mathrm{Y}}\right.$; all litters adjusted to 4 young) averaged $27.7 \pm 2.9 \mathrm{~g}$ in $C$. russula, $30.2 \pm 3.1 \mathrm{~g}$ in $M$. domesticus and $28.7 \pm 5.1 \mathrm{~g}$ in $M$. arvalis. It was correlated with female body mass in the three species $(r=0.83$, 0.65 and 0.65 , respectively; all $P<0.05)$. $\mathrm{RMR}_{\mathrm{L}}$ was correlated with $m_{\mathrm{Y}}$ in all species, but the partial correlation between $\mathrm{RMR}_{\mathrm{L}}$ and litter mass, while controlling for female mass, was significant only in C. russula $(r=0.57 ; t=2.78 ; d f=16 ; P<0.05)$. Thus a second ANCOVA was done in this species on $\mathrm{RMR}_{\mathrm{L}}$ values corrected for the effect of litter mass. The results of this analysis were very similar and are not given here.

\subsection{Individual variation in metabolic change between the two reproductive states}

The difference between BMR and $\mathrm{RMR}_{\mathrm{L}}$ showed large individual variation: $\left(\mathrm{RMR}_{\mathrm{L}}-\mathrm{BMR}\right)$ ranged from 3.4 to $15.4 \mathrm{mLO}_{2} \mathrm{~h}^{-1}$ in C. russula, from 1.1 to $20.0 \mathrm{mLO}_{2} \mathrm{~h}^{-1}$ in M. domesticus and from -6.0 to $11.1 \mathrm{mLO}_{2} \mathrm{~h}^{-1}$ in M. arvalis (Figs. 1-3). When expressed as a percentage of the BMR measured in the same female, $\mathrm{RMR}_{\mathrm{L}}$ varied from $115 \%$ to $179 \%$ in C. russula, $103 \%$ to $173 \%$ in M. domesticus and $90 \%$ to $115 \%$ in M. arvalis.

The change in rate of metabolism between the NL and $\mathrm{L}$ states, $\log \Delta \mathrm{MR}$, was significantly and negatively correlated with the level of BMR (resBMR) in the mice (Pearson's $r=$ $-0.75 ; P<0.001)$ but not in the shrews $(r=-0.24 ; P=0.32)$ and the voles $(r=0.26 ; P=0.44)$. However, as already suggested, variations in female body mass, in female body mass change between the two states and/or in litter mass may affect this relationship. The partial correlation between $\log \Delta \mathrm{MR}$ and resBMR, while controlling for $\log m_{\mathrm{NL}}, \log \Delta m$ and $\operatorname{res} m_{\mathrm{Y}}$, was highly significant and negative in $C$. russula $(r=-0.73 ; t=3.97$; $d f=14 ; P<0.01)$ and $M$. domesticus $(r=-0.78 ; t=5.49 ; d f=19$; $P<0.001)$. In $M$. arvalis it was not significant $(r=0.004 ; t=0.01$; $d f=6 ; P>0.9)$, but the sample size in this species was much

Table 2

Tests of the effect of the reproductive state on the rate of metabolism in the three species under study

\begin{tabular}{|c|c|c|c|}
\hline & Crocidura russula & $\begin{array}{l}\text { Mus } \\
\text { domesticus }\end{array}$ & $\begin{array}{l}\text { Microtus } \\
\text { arvalis }\end{array}$ \\
\hline$N$ & 19 & 24 & 11 \\
\hline \multicolumn{4}{|l|}{$\begin{array}{l}\text { Error: factor } \\
\quad \text { (individual) }\end{array}$} \\
\hline $\log m$ & $\begin{array}{l}1 ; 0.031 ; 29.3 \\
<0.0001\end{array}$ & $\begin{array}{l}1 ; 0.049 ; \mathbf{3 7 . 3} \\
<0.0001\end{array}$ & $\begin{array}{l}1 ; 0.031 ; \mathbf{2 8 . 5} \\
0.0007\end{array}$ \\
\hline $\begin{array}{l}\log m * \text { factor } \\
\quad \text { (reproductive } \\
\text { state) }\end{array}$ & $\begin{array}{l}1 ; 0.004 ; \mathbf{3 . 5 5} \\
0.08\end{array}$ & $\begin{array}{l}1 ; 0.0001 ; \mathbf{0 . 0 8} \\
0.78\end{array}$ & $\begin{array}{l}1 ; 0.042 ; \mathbf{3 . 8 9} \\
0.08\end{array}$ \\
\hline Residuals & $16 ; 0.017$ & $21 ; 0.027$ & $8 ; 0.009$ \\
\hline \multicolumn{4}{|l|}{ Error: within } \\
\hline $\log m$ & $\begin{array}{l}1 ; 0.188 ; \mathbf{2 2 3} \\
<0.0001\end{array}$ & $\begin{array}{l}1 ; 0.104 ; \mathbf{6 8 . 4} \\
<0.0001\end{array}$ & $\begin{array}{l}1 ; 0.000003 ; \\
\mathbf{0 . 0 0 5} ; 0.94\end{array}$ \\
\hline $\begin{array}{l}\text { Factor } \\
\text { (reproductive } \\
\text { state) }\end{array}$ & $\begin{array}{l}1 ; 0.042 ; \mathbf{5 0 . 1} \\
<0.0001\end{array}$ & $\begin{array}{l}1 ; 0.023 ; 14.9 \\
0.009\end{array}$ & $\begin{array}{l}1,0.01 ; \mathbf{1 9 . 5} \\
0.002\end{array}$ \\
\hline $\begin{array}{l}\log m * \text { factor } \\
\text { (reproductive } \\
\text { state) }\end{array}$ & $\begin{array}{l}1 ; 0.002 ; \mathbf{2 . 2 3} \\
0.15\end{array}$ & $\begin{array}{l}1 ; 0.0008 ; \mathbf{0 . 5 4} \\
0.47\end{array}$ & $\begin{array}{l}1 ; 0.003 ; \mathbf{0 . 5 1} \\
0.50\end{array}$ \\
\hline Residuals & $16 ; 0.013$ & $21 ; 0.032$ & $8 ; 0.004$ \\
\hline
\end{tabular}

For each species, full results of the repeated measures ANCOVA are given with, for each source of variation, the degrees of freedom $(d f)$, the sum of squares and, when appropriate, the $F$ value (in bold) and its associated probability level ( $P$, in italics). Two levels are considered in such analyses: the "between-individuals" level (Error: factor (individual)) and the "within-individuals" level (error: within). 
smaller. Thus, other things being equal, female shrews and mice with a lower than average BMR tended to show a larger than average increase in rate of metabolism during lactation.

The pattern detected in shrews and mice can be easily illustrated with $M$. domesticus, in which the intraspecific scaling exponent for BMR was close to 0.75 (0.93, with $95 \%$ confidence intervals ranging between 0.34 and 1.36; Table 1 and Fig. 2). The studied population can be divided into two metabolic groups, characterized by a BMR of less than $100 \%$ and more than $100 \%$ of predicted by the Kleiber equation, respectively (mice on each side of the dashed line on Fig. 2). The low-BMR group would have increased its relative rate of metabolism from an average BMR of $94 \%$ to an average $\mathrm{RMR}_{\mathrm{L}}$ of $117 \%$ of Kleiber's equation. A smaller average increase would have been exhibited by lactating females of the highBMR group $\left(\mathrm{BMR}=113 \% ; \mathrm{RMR}_{\mathrm{L}}=121 \%\right.$ of predicted).

\section{Discussion}

\subsection{Basal rate of metabolism}

The average basal rate of metabolism obtained in this study for C. russula (Table 1) is only slightly lower than the value published by Sparti (1990) on shrews of the same population (106\% vs. $116 \%$ of predicted by the Kleiber equation). Part of the slight difference may be due to seasonal variation in both rate of metabolism and body mass, since Sparti (1990) measured wintering shrews which were on average slightly lighter (10.4 g). Rosenmann and Morrison (1974) and Richardson et al. (1994) provided data compatible with BMR determination on wild caught house mice. Their relative BMR estimates (102$113 \%$ ) are close to our values for M. domesticus (99\%), despite the fact that they were obtained with smaller mice from very distant regions. In laboratory mice, measurements meeting the requirements for BMR estimation provided relative average values ranging from slightly less than $100 \%$ to $148 \%$ (Rosenmann and Morrison, 1974; Lacy and Lynch, 1979; Hayes et al., 1992; Konarzewski and Diamond, 1994; Richardson et al., 1994; Speakman and McQueenie, 1996; Johnson et al., 2001a). Given that the various strains of the laboratory mouse have been submitted to long-lasting artificial selection, these data can hardly be compared with values on wild caught mice (e.g. see Richardson et al., 1994). As for M. arvalis, BMR estimates available for individuals from eastern Europe $\left(60.2 \mathrm{mLO}_{2} \mathrm{~h}^{-1}\right.$ or $163 \%$ of predicted for animals weighing on average $23.9 \mathrm{~g}$; Jansky, 1959; Trojan and Wojciechowska, $1967)$ are much higher than ours (128\%). Part of this discrepancy may be due to technical problems (e.g. the use of a closed-circuit respirometer by these authors, which makes it difficult to eliminate the effect of activity), but differences in body mass and other local adaptations in this wide ranging species may also be involved.

\subsection{Comparison between average $B M R$ and average $R M R_{L}$}

Resting rate of metabolism during lactation $\left(\mathrm{RMR}_{\mathrm{L}}\right)$ was higher than BMR in C. russula, M. domesticus and M. arvalis, the difference between these two rates being in each species larger than could be accounted for by changes in body mass. These results do not fit into Thompson and Nicoll's (1986) analysis, according to which species with a BMR higher than expected show little increase in reproductive RMR.

Many studies have been carried out on the metabolic changes associated with reproduction in mammals (e.g. see the review of Thompson, 1992). However, only few of them allow a comparison between the BMR and the maternal rate of metabolism during either gestation or lactation. Indeed, the first condition that must be met for such a comparison is that the measurements of the rate of metabolism must meet the criteria for BMR, except for the reproductive state of the mothers when measuring maternal RMR. For example, metabolic measurements made on resting individuals below thermal neutrality (e.g. on Suncus murinus, Dryden et al., 1974; on M. arvalis, Trojan and Wojciechowska, 1967; on Sigmodon hispidus, Randolph et al., 1977), which have been cited by Thompson and Nicoll (1986), include energy expended for thermoregulation and depend to a large extent on ambient temperature, body temperature and minimal thermal conductance (McNab, 2002). They are therefore inadequate to detect a metabolic shift from basal levels. In addition, as already pointed out by McNab (1997), some species of mammals normally do not maintain a normothermic body temperature when resting and do not exhibit a thermoneutral zone, such that they cannot be assigned a basal rate of metabolism. Some tenrecs (e.g. Microgale dobsoni, Stephenson and Racey, 1993a; Geogale aurita, Stephenson and Racey, 1993b) may fall into this category (but see below).

A comparison between maternal RMR and BMR also rests on the condition that both parameters are measured during the same study, with the same population and, if possible, on the same individuals, because there is now ample evidence that intraspecific variation in rate of metabolism can be large (Earle and Lavigne, 1990; Hayes et al., 1992; McLean and Speakman, 2000; this study). Values of BMR and maternal RMR obtained on different individuals of the same population are adequate when sample size is sufficiently large. But studies providing only values for maternal RMR (e.g. on Didelphis virginiana, Fleming et al., 1981) which have to be compared with BMR data obtained by other authors and/or on other populations include sources of variation (geographical, technical) that should clearly be controlled. Even if sources of variation are reduced to a minimum, within-individual variation in body mass, which may be appreciable in small mammals (McLean and Speakman, 2000), should be considered when comparing different reproductive stages, because body mass is a major determinant of the rate of metabolism.

Another complication comes from the fact that rate of metabolism varies along a reproductive event, a variation which partly depends on the species (Thompson and Nicoll, 1986; Nicoll and Thompson, 1987; Mover et al., 1989; Stephenson and Racey, 1993a; Garton et al., 1994; Harder et al., 1996; Künkele and Trillmich, 1997; McLean and Speakman, 2000). In the present study, $\mathrm{RMR}_{\mathrm{L}}$ has been measured only once around peak lactation, both to permit a comparison across individuals or species in a state of maximum reproductive effort (Genoud 
Table 3

Body mass, BMR and RMR during lactation in small mammals

\begin{tabular}{|c|c|c|c|c|c|c|c|c|c|}
\hline \multirow[t]{3}{*}{ Species } & \multicolumn{4}{|c|}{ NL state } & \multicolumn{4}{|c|}{ L state } & \multirow[t]{3}{*}{ References } \\
\hline & \multirow[t]{2}{*}{$N$} & \multirow{2}{*}{$\frac{\text { Mass }}{(\mathrm{g})}$} & \multicolumn{2}{|l|}{ BMR } & \multirow[t]{2}{*}{$\mathrm{N}$} & \multirow{2}{*}{$\frac{\text { Mass }}{(\mathrm{g})}$} & \multicolumn{2}{|l|}{$\mathrm{RMR}_{\mathrm{L}}$} & \\
\hline & & & $\left(\mathrm{mLO}_{2} \mathrm{~h}^{-1}\right)$ & $\%$ & & & $\left(\mathrm{mLO}_{2} \mathrm{~h}^{-1}\right)$ & $\%$ & \\
\hline \multicolumn{10}{|l|}{ Metatheria } \\
\hline Monodelphis domestica & 19 & 64.1 & $49.1 *$ & 63 & 20 & $82 *$ & $120 *$ & 129 & Harder et al., 1996 \\
\hline Monodelphis domestica & 5 & 82.0 & $59.5^{*}$ & 64 & $5^{* *}$ & & $98.8^{*}$ & 106 & Thompson and Nicoll, 1986 \\
\hline \multicolumn{10}{|l|}{ Eutheria (wild) } \\
\hline Echinops telfairi & 1 & 141 & $39.1^{*}$ & 28 & $1 * *$ & & $119^{*}$ & 85 & Thompson and Nicoll, 1986 \\
\hline Echinops telfairi & 1 & 153 & $40.1^{*}$ & 27 & $1 * *$ & & $77 *$ & 52 & Nicoll and Thompson, 1987 \\
\hline Plecotus auritus & 14 & 10.7 & 14.7 & 73 & 4 & 9.6 & 19.9 & 107 & McLean and Speakman, 2000 \\
\hline Microgale talazaci & 3 & 47.1 & $46.6^{*^{+}}$ & 76 & 2 & $57^{*}$ & $60 *$ & 85 & Stephenson and Racey, 1993a \\
\hline Ctenomys talarum & 9 & 118 & 95.5 & 78 & 9 & 129 & 144 & 110 & Zenuto et al., 2002 \\
\hline Elephantulus rufescens & 3 & 84.1 & 77.9 & 82 & $3 * *$ & & $110^{*}$ & 116 & Thompson and Nicoll, 1986 \\
\hline Akodon azarae & 8 & 26.3 & 39.0 & 98 & 7 & 29.0 & 86.7 & 203 & Antinuchi and Busch, 2001 \\
\hline Mus domesticus & 24 & 22.8 & 35.3 & 99 & $24 * *$ & 24.9 & 44.4 & 116 & This study \\
\hline Crocidura russula & 19 & 11.3 & 22.4 & 106 & $19 * *$ & 12.8 & 32.1 & 139 & This study \\
\hline Mesocricetus auratus & 21 & 112 & $125++$ & 106 & 16 & 112 & $164++$ & 139 & Garton et al., 1994 \\
\hline Microtus arvalis & 11 & 33.9 & 61.4 & 128 & $11^{* *}$ & 28.6 & 66.3 & 157 & This study \\
\hline Crocidura suaveolens & & 9.0 & 22.9 & 129 & & $8.2^{*}$ & $30.2^{*}$ & 182 & Mover et al., 1989 \\
\hline Microgale cowani & 2 & 10.3 & $27.0^{+}$ & 137 & 1 & 10.3 & 37.1 & 189 & Stephenson and Racey, 1993a \\
\hline \multicolumn{10}{|c|}{ Eutheria (laboratory form) } \\
\hline Mus musculus & 71 & 27.1 & 44.6 & 110 & $71 * *$ & 44.3 & 97.6 & 166 & Johnson et al., 2001a,b \\
\hline Mus musculus & 9 & 24.8 & 56.2 & 148 & 8 & 38.8 & 141 & 265 & Speakman and McQueenie, 1996 \\
\hline
\end{tabular}

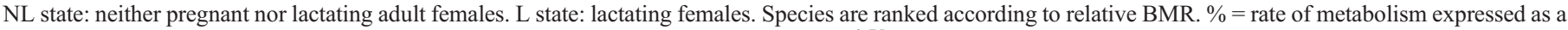

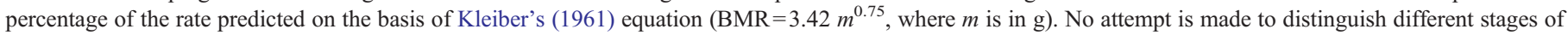

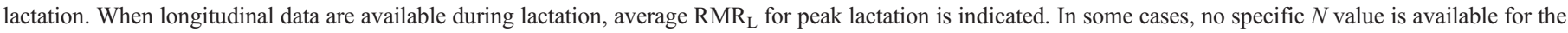
data indicated; when no specific body mass data is given for $\mathrm{RMR}_{\mathrm{L}}$, relative $\mathrm{RMR}_{\mathrm{L}}(\%)$ is calculated on the basis of the $\mathrm{NL}$ body mass.

*Value recalculated or estimated from a figure. ${ }^{+}$Thermoneutral zone uncertain. ${ }^{* *}$ Same individuals as for the NL state.

++ Values corrected to an average body mass of $111.9 \mathrm{~g}$ and an average body temperature of $36.6{ }^{\circ} \mathrm{C}$.

and Vogel, 1990; Cretegny, 1997; personal observations) and to avoid multiple disturbances of the lactating females and their litter. During gestation, small mammals show variations in the RMR that largely reflect variations in body mass. However, both positive and negative deviations from the value predicted for a nonreproductive female of the same mass and species have been found (Mover et al., 1988; Stephenson and Racey, 1993a; Garton et al., 1994; Harder et al., 1996; McLean and Speakman, 2000; Antinuchi and Busch, 2001; Zenuto et al., 2002). Further interspecific and intraspecific studies on the RMR of pregnant small mammals would clearly be of interest, especially if these studies would also control for the effects of body mass. In addition, Mover et al. (1989) have shown for $C$. suaveolens that the RMR of lactating females was strongly increased above the nonreproductive level, whereas that of females which were simultaneously pregnant and lactating remained close to BMR. When compared to lactation alone, simultaneous pregnancy and lactation was also associated with a significantly lower RMR in female laboratory mice, once body mass effects were controlled for (Johnson et al., 2001b). In our study, female common voles still exhibited an elevated $\mathrm{RMR}_{\mathrm{L}}$ although most of them were simultaneously pregnant and lactating.

With the above restrictions, data permitting comparison of $\mathrm{RMR}_{\mathrm{L}}$ with BMR in small mammals are quite scarce, although they are already scattered across major taxonomic groups (Table 3). $\mathrm{RMR}_{\mathrm{L}}$ tends to be higher than BMR in all species included, such that there seems to be no reason, at this stage, to explain the increased maternal rate of metabolism of low-BMR species in a way that is specific to them. Therefore, this limited data set does not provide much support for Thompson and Nicoll's (1986) hypothesis that predicted BMR according to the Kleiber equation may reflect an "advantageous or essential energetic regime" for therian reproduction. At least, the increased maternal rate of metabolism in low-BMR species can hardly be considered as support for this hypothesis.

Among the measurements that were discarded from Table 3, it is worth mentioning those published on tenrecs by Stephenson and Racey (1993a,b). These authors examined the relationship between RMR and ambient temperature in Microgale dobsoni and Geogale aurita, and showed that neither of them exhibited a thermoneutral zone. However, they measured RMR in nonreproductive individuals and reproducing females of several species of tenrecs under the same experimental conditions at around $30{ }^{\circ} \mathrm{C}$. On the basis of these results, they already concluded that the tenrecs do not fit into the scheme of Thompson and Nicoll (1986), since RMR was higher in reproducing females regardless of the average nonreproductive RMR of the species. Unfortunately, Stephenson and Racey (1993a) could measure only a single lactating female of the only species which exhibited at around $30{ }^{\circ} \mathrm{C}$ an RMR higher than the value expected from the Kleiber curve (Microgale cowani, $137 \%$, Table 3). 
The proposal that rate of metabolism is increased in reproducing female mammals mainly because of the increased size and/or activity of various tissues and organs (Hammond and Diamond, 1992; Thompson, 1992; Hammond et al., 1994; Speakman and McQueenie, 1996) receives much better support from the available data. Indeed, this proposal does not lead to the prediction of a drastically different pattern of metabolic change during reproduction in low-BMR and high-BMR species. In fact, there is evidence for the laboratory mouse that the digestive tract, liver, kidneys, heart and lungs all increase in size in reproducing females (Hammond and Diamond, 1992; Hammond et al., 1994; Speakman and McQueenie, 1996; Johnson et al., 2001a). Hammond and Diamond (1992) have also shown that the morphological changes undergone by the intestine during reproduction are linked to functional changes. Furthermore, Speakman and McQueenie (1996) found that rate of metabolism was linked to the size of the digestive tract. Similar anatomical and functional changes probably also occur in reproducing females of wild mammals. Nevertheless, the present data do not rule out a possible interspecific link between the metabolic changes occurring during lactation and the average relative BMR. A test of this hypothesis would require consideration of the potential effect of phylogenetic non-independence (Felsenstein, 1985; Garland et al., 1992; but see also McNab, 2002; Martin et al., 2005) as well as a much larger data set than presently available.

\subsection{Individual variation in metabolic change during reproduction}

In $C$. russula and $M$. domesticus, the change in wholeindividual rate of metabolism which occurred between the NL and L states $(\log \Delta \mathrm{MR})$ was negatively correlated with resBMR, the residual of the linear regression between $\log B M R$ and $\log m_{\mathrm{NL}}$, when the effects of female body mass and litter mass were controlled for. Thus, within these two species and other things being equal, females exhibiting a lower than average BMR tended to exhibit a larger increase in rate of metabolism during lactation. This intraspecific pattern has not been observed previously. The few studies which reported data on both BMR and $\mathrm{RMR}_{\mathrm{L}}$ in wild small mammals (Table 3 ) either did not provide measurements for both parameters in the same female, or were based on a limited sample size, such that a quantitative analysis of the pattern was out of reach. Assessing the extent and significance of the intraspecific pattern depicted here will obviously require many more data on a diverse set of small mammal species.

Individual variation in fat content and use may initially be proposed as an explanation for the larger increase in rate of metabolism exhibited at a given body mass by low-BMR females. Body fat is characterized by a very low rate of metabolism (e.g. see Nelson et al., 1992) such that changes in whole-individual rate of metabolism should indeed be observed when fat is deposited or used. Even small mammals often exhibit fat deposition and use in relation to reproduction (e.g. Randolph et al., 1977; Millar, 1987; Weiner, 1987; Liu et al., 2003) despite the fact that they usually cover the additional costs of reproduction largely by increasing food ingestion (Mattingly and McClure, 1982, 1985; McClure, 1987; Thompson, 1992). Fat content and use was not assessed in our study, but the results demonstrate that fat utilization alone cannot account for the metabolic changes observed in the three species. Indeed, if fat use was the sole process involved, body mass should also have been reduced during lactation. A slight reduction in body mass was observed in M. arvalis, but in both $C$. russula and $M$. domesticus body mass was significantly larger during lactation and it is precisely in the latter two species that the negative relationship between BMR and the extent of metabolic increase was detected.

Presumably, the relationship between BMR and the change in whole-individual rate of metabolism between the NL and $\mathrm{L}$ states is at least partly the consequence of a relationship between the profound physiological and anatomical changes which females undergo during lactation (Hammond and Diamond, 1992; Hammond et al., 1994; Speakman and McQueenie, 1996; Johnson et al., 2001a) and the level of BMR at any given body mass. Together with these data, our results suggest that, at any body mass within at least some small mammal species, females with a lower than average BMR exhibit more extensive physiological and/or anatomical modifications in relation to reproduction, which is reflected in the larger observed increase in whole-individual rate of metabolism.

$\mathrm{McNab}$ (1980) has proposed that part of the variation in BMR among mammals may be linked to variation in reproductive output and that one advantage of having a higher relative BMR may be the larger reproductive output that can be achieved. This proposal has been tested at the interspecific level by several authors, with contrasting results (Hennemann, 1983; Glazier, 1985; Harvey et al., 1991), whereas at the intraspecific level not much support has been found (Derting and McClure, 1989; Earle and Lavigne, 1990; Hayes et al., 1992; Johnson et al., 2001a; Krol et al., 2003; but see Derting, 1989). As already suggested by Speakman and McQueenie (1996), McLean and Speakman (2000) and Johnson et al. (2001a) the fact that maternal rates of metabolism may be elevated above nonreproductive levels may explain why some studies have failed to obtain a correlation between BMR and reproductive output. The negative correlation that we found in C. russula and $M$. domesticus between the level of BMR and the increase in rate of metabolism during lactation may also explain the failure to detect a relationship between BMR and reproductive output at the intraspecific level. For example, different conspecific females of the same body mass but with a different BMR may achieve a similar reproductive output in captivity inasmuch as they make different anatomical and physiological adjustments for reproduction. However, all of these strategies might not necessarily be available under natural conditions, as the adjustments that they imply during reproduction may themselves not be without any cost. Thus, intraspecific variation in BMR may be related only indirectly to reproductive output, such that the relationship may be difficult to demonstrate in the optimal energetic conditions of the laboratory.

\section{Acknowledgements}

We thank Roland Hübner for helping us catching the mice and Marianne Besson who assisted us with the maintenance of 
the animals. Thanks are also due to Pierre Fontanillas, Jérôme Goudet and Nicolas Perrin who provided statistical advice. We are very grateful to Peter Vogel, Robert D. Martin and an anonymous referee for their valuable comments on the manuscript.

\section{References}

Antinuchi, C.D., Busch, C., 2001. Reproductive energetics and thermoregulatory status of nestlings in pampas mice Akodon azarae (Rodentia: Sigmodontinae). Physiol. Biochem. Zool. 74, 319-324.

Cretegny, C. 1997. Quelques facteurs affectant, durant la lactation, la croissance du campagnol des champs, Microtus arvalis. PhD Thesis, University of Lausanne, Lausanne, Switzerland.

Depocas, F., Hart, J.S., 1957. Use of the Pauling oxygen analyzer for measurement of oxygen consumption of animals in open-circuit systems and in a short-lag, closed-circuit apparatus. J. Appl. Physiol. 10, 388-392.

Derting, T.L., 1989. Metabolism and food availability as regulators of production in juvenile cotton rats. Ecology 70, 587-595.

Derting, T.L., McClure, P.A., 1989. Intraspecific variation in metabolic rate and its relationship with productivity in the cotton rat Sigmodon hispidus. J. Mammal. 70, 520-531.

Dryden, G.L., Gebczynski, M., Douglas, E.L., 1974. Oxygen consumption by nursling and adult musk shrews. Acta Theriol. 19, 453-461.

Earle, M., Lavigne, D.M., 1990. Intraspecific variation in body size, metabolic rate, and reproduction of deer mice (Peromyscus maniculatus). Can. J. Zool. $68,381-388$.

Felsenstein, J., 1985. Phylogenies and the comparative method. Am. Nat. 125, $1-15$.

Fleming, M.W., Harder, J.D., Wukie, J.J., 1981. Reproductive energetics of the Virginia opossum compared with some eutherians. Comp. Biochem. Physiol., B 70, 645-648.

Garland Jr., T., Harvey, P.H., Ives, A.R., 1992. Procedures for the analysis of comparative data using phylogenetically independent contrasts. Syst. Biol. $41,18-32$.

Garton, D.W., Hsu, M.J., Harder, J.D., 1994. Environmental temperature and metabolic rates during gestation and lactation in golden hamsters (Mesocricetus auratus). Physiol. Zool. 67, 497-514.

Genoud, M., 1990. Seasonal variations in the basal rate of metabolism of subtropical insectivorous bats (Nycticeius humeralis and Lasiurus seminolus): a comparison with other mammals. Rev. Suisse Zool. 97, 77-90.

Genoud, M., Ruedi, M., 1996. Rate of metabolism, temperature regulation, and evaporative water loss in the lesser gymnure Hylomys suillus (Insectivora, Mammalia). J. Zool. Lond. 240, 309-316.

Genoud, M., Vogel, P., 1990. Energy requirements during reproduction and reproductive effort in shrews (Soricidae). J. Zool. Lond. 220, 41-60.

Gessaman, J.A., 1973. Methods of estimating the energy cost of free existence. In: Gessaman, J.A. (Ed.), Ecological Energetics of Homeotherms. Utah State University Press, Logan, pp. 3-31.

Glazier, D.S., 1985. Relationship between metabolic rate and energy expenditure for lactation in Peromyscus. Comp. Biochem. Physiol., A 80, 587-590.

Hammond, K.A., Diamond, J., 1992. An experimental test for a ceiling on sustained metabolic rate in lactating mice. Physiol. Zool. 65, 952-977.

Hammond, K.A., Konarzewski, M., Torres, R.M., Diamond, J., 1994. Metabolic ceilings under a combination of peak energy demands. Physiol. Zool. 67, $1479-1506$.

Harder, J.D., Hsu, M.J., Garton, D.W., 1996. Metabolic rates and body temperature of the gray short-tailed opossum (Monodelphis domestica) during gestation and lactation. Physiol. Zool. 69, 317-339.

Harvey, P.H., Pagel, M.D., Rees, J.A., 1991. Mammalian metabolism and life histories. Am. Nat. 137, 556-566.

Hayes, J.P., Garland, T., Dohm, M.R., 1992. Individual variation in metabolism and reproduction of Mus: are energetics and life history linked? Funct. Ecol. 6, 5-14.

Hayssen, V., 1984. Basal metabolic rate and the intrinsic rate of increase: and empirical and theoretical reexamination. Oecologia 64, 419-424.

Hennemann, W.W., 1983. Relationship among body mass, metabolic rate and the intrinsic rate of natural increase in mammals. Oecologia 56, 104-108.
Hübner, R., 1995. Mus domesticus Rutty, 1772. In: Hausser, J. (Ed.), Mammifères de la Suisse. Birkhäuser Verlag, Basel, pp. 293-297.

Ihaka, R., Gentleman, R., 1996. R: a language for data analysis and graphics. J. Comput. Graph. Stat. 5, 299-314.

Jansky, L., 1959. Working oxygen consumption in two species of wild rodents (Microtus arvalis, Clethrionomys glareolus). Physiol. Bohemoslov. 8, 472-478.

Jeanmaire-Besançon, F., 1986. Estimation de l'âge et de la longévité chez Crocidura russula (Insectivora: Soricidae). Acta Oecol., Oecol. Appl. 7, 355-366.

Jeanmaire-Besançon, F., 1988. Sexual maturity of Crocidura russula (Insectivora: Soricidae). Acta Theriol. 33, 111-119.

Johnson, M.S., Thomson, S.C., Speakman, J.R., 2001a. Limits to sustained energy intake. II. Inter-relationships between resting metabolic rate, lifehistory traits and morphology in Mus musculus. J. Exp. Biol. 204, 1937-1946.

Johnson, M.S., Thomson, S.C., Speakman, J.R., 2001b. Limits to sustained energy intake. III. Effects of concurrent pregnancy and lactation in Mus musculus. J. Exp. Biol. 204, 1947-1956.

Kleiber, M., 1961. The Fire of Life: An Introduction to Animal Energetics. John Wiley, New York. 454 pp.

Konarzewski, M., Diamond, J., 1994. Peak sustained metabolic rate and its individual variation in cold stressed mice. Physiol. Zool. 67, 1186-1212.

Krol, E., Johnson, M.S., Speakman, J.R., 2003. Limits to sustained energy intake. VIII. Resting metabolic rate and organ morphology of laboratory mice lactating at thermoneutrality. J. Exp. Biol. 206, 4283-4291.

Ksiazek, A., Konarzewski, M., Lapo, I.B., 2004. Anatomic and energetic correlates of divergent selection for basal metabolic rate in laboratory mice. Physiol. Biochem. Zool. 77, 890-899.

Künkele, J., Trillmich, F., 1997. Are precocial young cheaper? Lactation energetics in the guinea pig. Physiol. Zool. 70, 589-596.

Lacy, R.C., Lynch, C.B., 1979. Quantitative genetic analysis of temperature regulation in Mus musculus. I. Partitioning of variance. Genetics 91, $743-753$.

Liu, H., Wang, D.H., Wang, Z.W., 2003. Energy requirements during reproduction in female Brandt's voles (Microtus brandtii). J. Mammal. 84, $1410-1416$

Macholan, M., 1999. Mus domesticus Schwarz and Schwarz, 1943. In: Mitchell-Jones, A.J., Amori, G., Bogdanowicz, W., Krystufek, B., Reijnders, P.J.H., Spitzenberger, F., Stubbe, M., Thissen, J.B.M., Vohralik, V., Zima, J. (Eds.), The Atlas of European Mammals. Academic Press, Poyser, London, pp. 282-283.

Martin, R.D., Genoud, M., Hemelrijk, C.K., 2005. Problems of allometric scaling analysis: examples from mammalian reproductive biology. J. Exp. Biol. 208, 1731-1747.

Mattingly, D.K., McClure, P.A., 1982. Energetics of reproduction in largelittered cotton rats (Sigmodon hispidus). Ecology 63, 183-195.

Mattingly, D.K., McClure, P.A., 1985. Energy allocation during lactation in cotton rats (Sigmodon hispidus) on a restricted diet. Ecology 66, 928-937.

McClure, P.A., 1987. The energetics of reproduction and life histories of cricetine rodents (Neotoma floridana and Sigmodon hispidus). Symp. Zool. Soc. Lond. 57, 241-258.

McLean, J.A., Speakman, J.R., 2000. Effects of body mass and reproduction on the basal metabolic rate of brown long-eared bats (Plecotus auritus). Physiol. Biochem. Zool. 73, 112-121.

McNab, B.K., 1980. Food habits, energetics, and the population biology of mammals. Am. Nat. 116, 106-124.

McNab, B.K., 1988. Complications inherent in scaling the basal rate of metabolism in mammals. Q. Rev. Biol. 63, 25-54.

McNab, B.K., 1997. On the utility of uniformity in the definition of basal rate of metabolism. Physiol. Zool. 70, 718-720.

McNab, B.K., 2002. The Physiological Ecology of Vertebrates: A View from Energetics. Cornell University Press, Ithaca, New York. 576 pp.

Merrit, J.F., Zegers, D.A., Rose, L.R., 2001. Seasonal thermogenesis of southern flying squirrels (Glaucomys volans). J. Mammal. 82, 51-64.

Millar, J.S., 1987. Energy reserves in breeding small rodents. Symp. Zool. Soc. Lond. 57, 231-240. 
Mover, H., Ar, A., Hellwing, S., 1989. Energetic costs of lactation with and without simultaneous pregnancy in the white-toothed shrew Crocidura russula monacha. Physiol. Zool. 62, 919-936.

Mover, H., Hellwing, S., Ar, A., 1988. Energetic cost of gestation in the whitetoothed shrew Crocidura russula monacha (Soricidae, Insectivora). Physiol. Zool. 61, 17-25.

Nelson, K.M., Weinsier, R.L., Long, C.L., Schutz, Y., 1992. Prediction of resting energy expenditure from fat-free mass and fat mass. Am. J. Clin. Nutr. 56, 848-856.

Nicoll, M.E., Thompson, S.D., 1987. Basal metabolic rates and energetics of reproduction in therian mammals: marsupials and placentals compared. Symp. Zool. Soc. Lond. 57, 7-27.

Randolph, P.A., Randolph, J.C., Mattingly, K., Foster, M.M., 1977. Energy costs of reproduction in the cotton rat, Sigmodon hispidus. Ecology 58, 31-45.

Richardson, C.S., Dohm, M.R., Garland, T., 1994. Metabolism and thermoregulation in crosses between wild and random-bred laboratory house mice (Mus domesticus). Physiol. Zool. 67, 944-975.

Rogowitz, G.L., McClure, P.A., 1995. Energy export and offspring growth during lactation in cotton rats (Sigmodon hispidus). Funct. Ecol. 9, 143-150.

Rosenmann, M., Morrison, P., 1974. Maximum oxygen consumption and heat loss facilitation in small homeotherms by $\mathrm{He}-\mathrm{O}_{2}$. Am. J. Physiol. 226, 490-495.

Sparti, A., 1990. Comparative temperature regulation of African and European shrews. Comp. Biochem. Physiol., A 97, 391-397.

Sparti, A., Genoud, M., 1989. Basal rate of metabolism and temperature regulation in Sorex coronatus and S. minutus (Soricidae: Mammalia). Comp. Biochem. Physiol., A 92, 359-363.
Speakman, J.R., McQueenie, J., 1996. Limits to sustained metabolic rate: the link between food intake, basal metabolic rate, and morphology in reproducing mice Mus musculus. Physiol. Zool. 69, 746-769.

Stephenson, P.J., Racey, P.A., 1993a. Reproductive energetics of the Tenrecidae (Mammalia: Insectivora). II. The shrew-tenrecs, Microgale spp. Physiol. Zool. 66, 664-685.

Stephenson, P.J., Racey, P.A., 1993b. Reproductive energetics of the Tenrecidae (Mammalia: Insectivora). I. The large-eared tenrec, Geogale aurita. Physiol. Zool. 66, 643-663.

Thompson, S.D. 1992. Gestation and lactation in small mammals : basal metabolic rate and the limits to energy use. In: Tomasi, T.E., Horton T.H., (Eds.), Mammalian energetics - Interdisciplinary views of metabolism and reproduction. Comstock Publishing Associates, Cornell University Press, Ithaca, 213-259.

Thompson, S.D., Nicoll, M.E., 1986. Basal metabolic rate and energetics of reproduction in therian mammals. Nature 321, 690-693.

Trojan, P., Wojciechowska, B., 1967. Resting metabolism rate during pregnancy and lactation in the European common vole - Microtus arvalis (Pall.). Ekol. Pol. 15A, 811-817.

Weiner, J., 1987. Limits to energy budget and tactics in energy investments during reproduction in the Djungarian hamster (Phodopus sungorus sungorus Pallas 1770). Symp. Zool. Soc. Lond. 57, 167-187.

Zenuto, R.R., Antinuchi, C.D., Busch, C., 2002. Bioenergetics of reproduction and pup development in a subterranean rodent (Ctenomys talarum). Physiol. Biochem. Zool. 75, 469-478. 